\title{
Enhancement of Toxic Gas Detecting Ability of Film Type Colorimetric Sensor
}

\author{
Sung Yeol Kim*, Seung Kyun Yoon*, Jungho Ahn, Dong June Chung\# \\ School of Chemical Engineering, Sungkyunkwan University, Suwon, Korea \\ Email: "djchung@skku.edu
}

Received 2 November 2015; accepted 5 January 2016; published 11 January 2016

\begin{abstract}
In this study, we tried to develop the in situ coating methods of hydrophilic polymer solution containing water soluble dye on nonwoven sheet for the colorimetric film sensor. And color change of coated dye according to contact various gas samples (as strong acid and base, chloroform, ammonia and HF) of this dye-coated nonwoven film was examined for the application of chemically toxic materials detecting tools in the actual site of working place without aid of any kinds of detecting devices. By the addition of electron transfer agent (quinone derivatives), quick color change behaviors were observed within 10 seconds under the contact of various toxic gases in general condition(room temperature, $50 \%$ humidity).
\end{abstract}

\section{Keywords}

Toxic Gas Detection, Colorimetric Sensor, pH Indicating Dyes, Polymer Binder, Electron Transfer Reagent

\section{Introduction}

For the assuring of worker's safety in actual work place in industry or factory handling various toxic gases, quick alarm devices without aid of any electronic tools is passionately required from the field. Colorimetric sensor is one of the powerful candidates about such requirements, but commercialized colorimetric sensors have weak points as relatively high price and late response time [1] [2]. So, in this study, we tried to develop cheap, rapidly detectable and also disposable colorimetric sensors using nonwoven sheet and $\mathrm{pH}$ indicating dye. Under the consideration of humid environment and external abrasion, hydrophilic polymer (sodium alginate; binder for dye coating) has very important role as the mediator of color changing reaction between coated dyes and introduced toxic gases and protective media to environment. Through in situ coating of sodium alginate/dye mixture solution on nonwoven sheet and consecutive curing process, film type colorimetric chemical sensors were obtained and such sensors were also available to attach on the clothes or hats of workers in the type of wearable and disposable device. Therefore early detection of gas leakages at the work place and effective warning in advance is possible, and such colorimetric sensor device can be confirm worker's safety from toxic gas leakage.

\footnotetext{
${ }^{*}$ These two persons have equal contribution on this paper.

${ }^{\#}$ Corresponding author.
}

How to cite this paper: Kim, S.Y., Yoon, S.K., Ahn, J. and Chung, D.J. (2016) Enhancement of Toxic Gas Detecting Ability of Film Type Colorimetric Sensor. Journal of Materials Science and Chemical Engineering, 4, 40-45.

http://dx.doi.org/10.4236/msce.2016.41008 


\section{Materials and Experiments}

\subsection{Materials}

For the colorimetric dye, we selected several $\mathrm{pH}$ indicator as bromophenolblue (BPB), boromocresol green (BCG), m-cresol purple (MCP), chlorophenol red (CPR), hydroquinone, benzoquinone and $\mathrm{CaCl}_{2}$ were purchased from Sigma-Aldrich Co. Ltd. (St. Louis, MO, USA). Sodium alginate (SA) was purchased from Yakuri Pure Chem. Co. (Kyoto, Japan) (Figure 1 and Figure 2) [3].

All reagents were used without any other purification. 8 kinds of toxic gase $\mathrm{s}\left(\mathrm{HCl}, \mathrm{Cl}_{2}, \mathrm{CH}_{3} \mathrm{NH}_{2}, \mathrm{NO}_{2}, \mathrm{HF}_{\text {, }}\right.$ $\mathrm{NH}_{3},\left(\mathrm{CH}_{3}\right)_{3} \mathrm{~N}, \mathrm{SO}_{2}$ ) were obtained from MG Tech. Co. (Hwasung, Korea).

\subsection{Experiments}

The $\mathrm{pH}$ indicating and water soluble dyes $\mathrm{p}$ indicatingdyes were mixed with hydrophilic binder(Sodium Alginate, SA) to $0.1 \mathrm{wt} \%$ of dye in $1 \mathrm{w} \%$ of SA aqueous solution with or without benzoquinone $(0.5 \mathrm{wt} \%)$, then this solution was coated on the nonwoven fabric sheet and cured with calcium chloride solution (10 wt\%) (Figure 3). After curing, coating layer on nonwoven sheet showed improvement of water repellency.

The coated nonwoven fabric sheet was dried under room temperature and exposed to the vaporized toxic gas for the confirmation of time dependent color change in these coating layers using following MFC apparatus (Model 247C, MG Tech Co., Hwasung, Korea) (Figure 4). The color changing behaviors were recorded by digital camera. These behaviors of manufactured colorimetric sensors were also confirmed by portable spectrophotometer (CM-2600d, Konica-Minolta, Tokyo, Japan) through the pre-Determined time schedule using CIELAB color space system.

\section{Results}

\subsection{Color changing Behaviors}

Figure 5 showed the time-dependent color change behaviors of dye coated colorimetric sensor (film type) after<smiles>O=S1(=O)OC(c2cc(Br)c(O)c(Br)c2)(c2ccccc2Br)c2ccccc21</smiles>

Bromophenol Blue<smiles>Cc1c(C2(c3cc(Br)c(O)c(Br)c3)OS(=O)(=O)c3ccccc32)cc(Br)c(O)c1Br</smiles>

Bromocresol Green<smiles>CC1=CC(=O)C=CC1=C(c1ccc(O)cc1C)c1ccccc1S(=O)(=O)[O-]</smiles>

m-Cresol Purple<smiles>O=S1(=O)OC(c2ccc(O)c(Cl)c2)(c2ccc(O)c(Cl)c2)c2ccccc21</smiles>

Chlorophenol Red

Figure 1. pH indicating dyes for gas detecting colorimetric sensor.

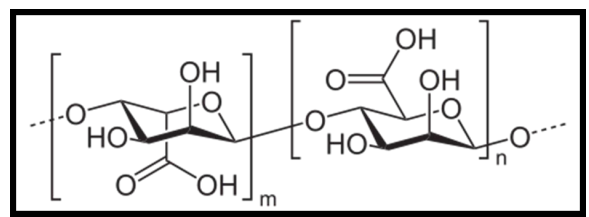

Figure 2. Chemical structure of sodium alginate.
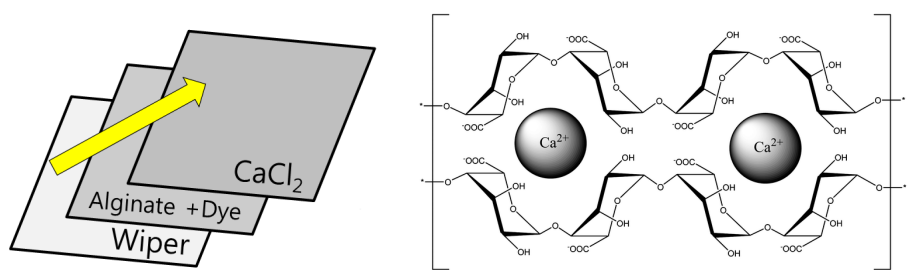

Figure 3. (Left) Impregnation coating method, (Right) Curing mechanism of SA with calcium chloride. 


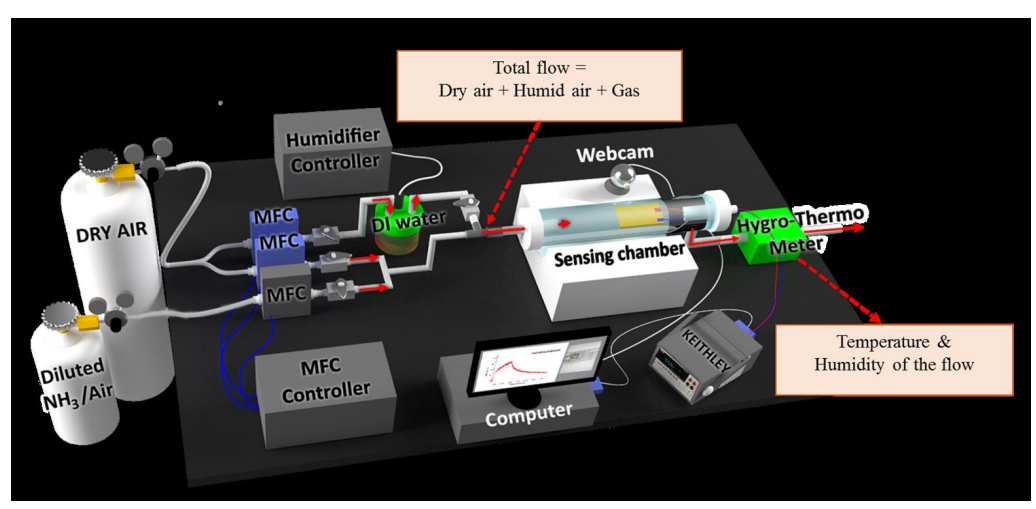

Figure 4. The apparatus for gas detection experiment using colorimetric film sensor.
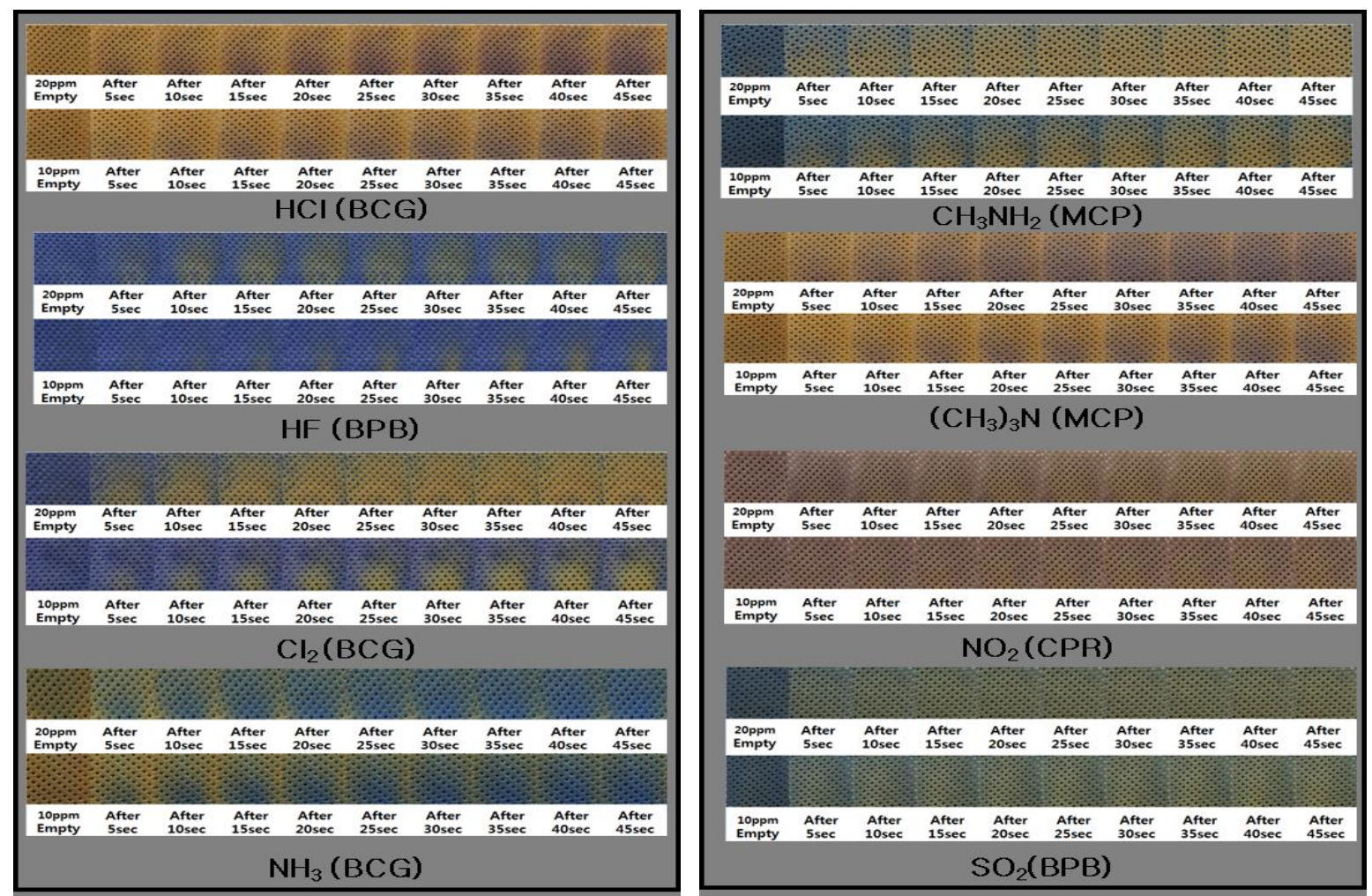

Figure 5. The time-depending color change behaviors after toxic gases exposure (8 types of gas).

toxic gases exposure through mass flow controller equipped gas supplier (8 kinds of toxic gases). In very short time (within 10 seconds) after gas exposure, all of the film type colorimetric sensors were changed their own color as blue to yellow or its reverse.

\subsection{Fast Color Changing Behaviors with Aid of Electron Transfer Agent}

The color changing behaviors of the film type colorimetric sensors (BPB dye coated) with (+/-) benzoquinone were shown in Figure 6. From the data of Figure 6(a), color changes owing to gas exposure ( $\mathrm{HCl}, 10 \mathrm{ppm})$ was observed after 30 seconds from initial state.

But, for the (+) benzoquinone, color changes owing to same condition was observed after 10 seconds from initial state (Figure 6(b). By the addition of benzoquinone which accelerates the electron transfer between dye and toxic gas on the basis of oxidation-reduction reaction, [4]-[6] the fast color changing was observed.

This means that electron transfer reagents which were worked in biochemical reactions of the living cell func- 
tion are also available in oxidation-reduction reaction of dyes in our system for colorimetric gas detection tool in working place.

\subsection{Water Resistance of Dye-Coated Layer on Colorimetric Film Sensor}

In most of working places treating toxic gases, working condition was exposed to very humid and high temperature. So water soluble dye component contained in coating layer of film type colorimetric sensor can be extracted out from the coating layer when exposed to the wet environment. And it will be also existed with high possibility that the coating layer can be dissolved under the same condition. Therefore, the water resistivity of coating layer containing water soluble dyes is essential characteristics of this colorimetric sensor. Figure 7 showed such behavior of prepared colorimetric sensor which made of sodium alginate solution containing BPB dye on non-woven sheet.

From the results of non-crosslinked film in Figure 7, most parts of coating layer consisting sodium alginate and dye was disappeared after washing. In case of crosslinked film with calcium chloride, the opposite was observed. This means that crosslinking effect of sodium alginate with $\mathrm{CaCl}_{2}$ was effective for the enhancement of water resistance of prepared film type colorimetric sensor. Considering of the pre-mentioned results, colorimetric sensors containing various dyes manufactured through in situ coating and crosslinking process using sodium alginate solution are very useful tool for the detection of toxic gases in working place with naked eye.

\subsection{Confirmation of Color Changing Behaviors by Spectrophotometer}

The International Commission on Illumination (CIE) first recommended the CIELAB color scale as a standard approximately, uniform color scale in 1976 [7], whereby colors are plotted in a cubic color space, as shown in Figure 8. The 4 dyes contained in the colorimetric film sensor is initially blue (or yellow) in color, and is converted to yellow(or blue) upon gas-contacting. The key parameters in color change are in $\mathrm{a}^{*}, \mathrm{~b}^{*}$ and $\mathrm{L}^{*}$, and $-\Delta(\mathrm{a}, \mathrm{b}$ and $\mathrm{L}) *$ is defined: $-\Delta \mathrm{a}$ (or $\mathrm{b}, \mathrm{L})^{*}=\mathrm{a}(\text { or } \mathrm{b}, \mathrm{L})^{*}$ dark $-\mathrm{a}(\text { or } \mathrm{b}, \mathrm{L})^{*}{ }_{\text {sample, } \mathrm{t}}$ where the 'dark' sample was the initial state of film sensor, but before subsequent gas contacting and "sample,t" refers to the film some time, $t$, after gas contact [8] [9]. The total color changing results $\left(\Delta \mathrm{E}^{*}\right)$ were expressed as following equation and summarized in Table 1 and Figure 9.

(a)

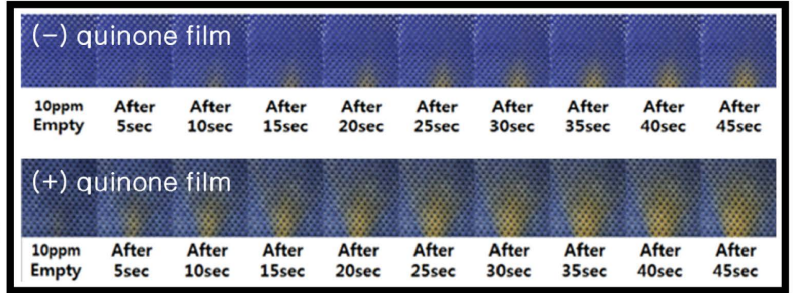

Figure 6. The difference of time-depending color change behaviors after toxic gases exposure with/without benzoquinone condition.

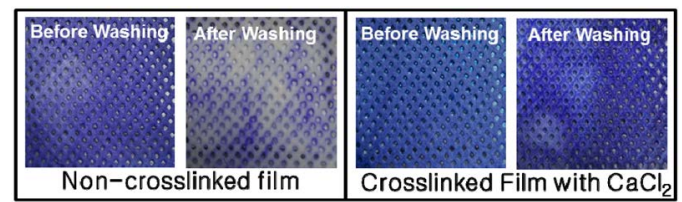

Figure 7. Crosslinking effect on water resistence of film sensor before/after washing in water.

Table 1. Degree of the color change by $\mathrm{L}^{*} \mathrm{a} * \mathrm{~b} *$ color coordinate (8 types of gases of $10 \mathrm{ppm}$ concentration).

\begin{tabular}{|c|c|c|c|c|c|c|c|c|}
\hline & $\mathbf{H C l}$ & $\mathbf{H F}$ & $\mathbf{C l}_{2}$ & $\mathbf{N H}_{3}$ & $\mathbf{C H}_{3} \mathbf{N H}_{2}$ & $\left(\mathbf{C H}_{3}\right)_{3} \mathbf{N}$ & $\mathbf{N O}_{2}$ & $\mathbf{S O}_{2}$ \\
\hline$\delta L^{*}$ & 12.96 & 7.02 & 15.11 & 18.72 & 18.48 & 11.01 & 6.23 & 8.12 \\
\hline$\delta a^{*}$ & 16.17 & -1.76 & 1.70 & 19.89 & -1.20 & -3.30 & -2.06 & 3.68 \\
\hline$\delta b^{*}$ & 35.80 & 28.35 & 46.29 & 46.15 & 37.35 & 22.82 & 11.41 & 18.70 \\
\hline$\delta E^{*}$ & 41.37 & 29.26 & 48.73 & 53.63 & 41.68 & 25.55 & 13.16 & 20.72 \\
\hline
\end{tabular}




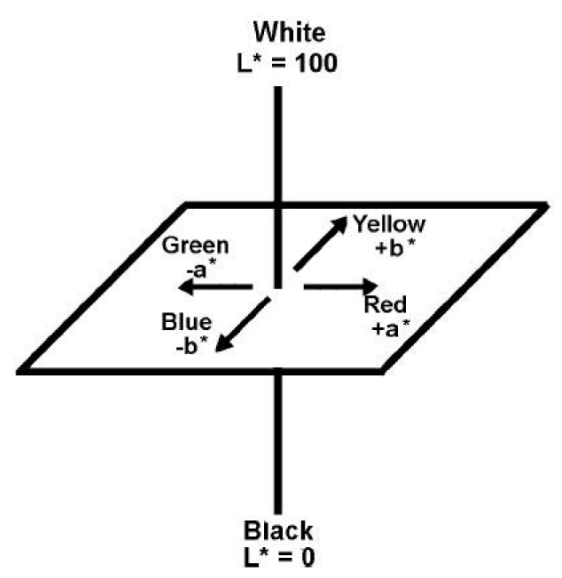

Figure 8. CIELAB color space.
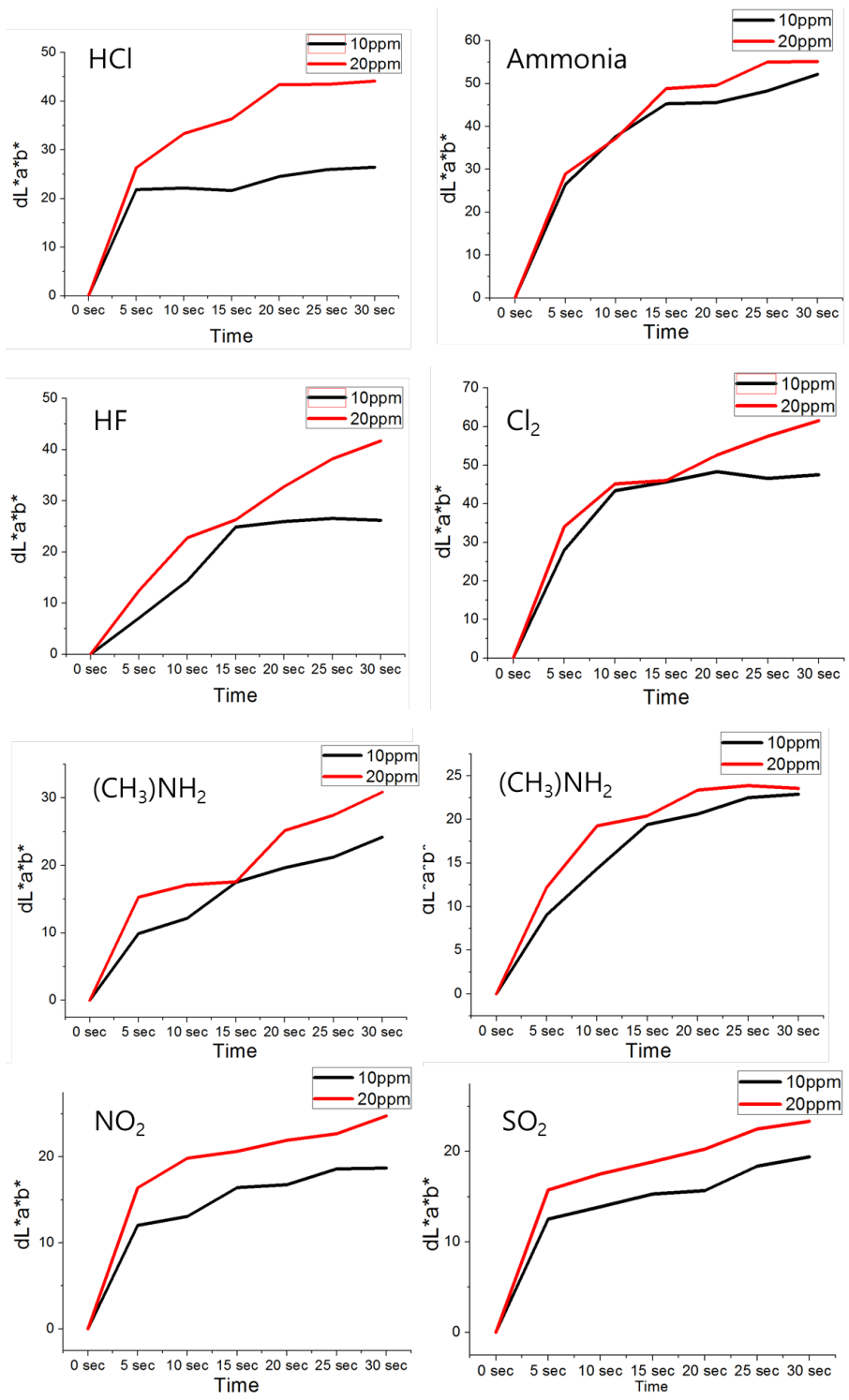

Figure 9. Behaviors of the color change after gas. 


$$
-\Delta \mathrm{E}^{*}=\left(\Delta \mathrm{L}^{* 2}+\Delta \mathrm{a}^{*^{2}}+\Delta \mathrm{b}^{*^{2}}\right)^{1 / 2}
$$

As shown in Figure 9, the color change as shown in the value of $\Delta \mathrm{E}$ was quickly increased within 5 seconds and completely converted to different color with gas contacting for 30 seconds in both 10 and 20 ppm gas concentration. The time dependent $\Delta \mathrm{E}$ value of $20 \mathrm{ppm}$ gas condition is greater than that of $10 \mathrm{ppm}$. These results mean that the color changes are able to detect with naked eye in a short period after gas contact in spite of diluted concentration of toxic gas and developed colorimetric film sensors are also available for toxic gas detection without aid of any kinds of detecting devices in working place.

\section{Acknowledgements}

This work was supported by the Fundamental Technology R\&D Program for Society of the National Research Foundation (NRF) funded by the Ministry of Science, ICT \& Future Planning (Grant No. 2013M3C8A 3075845).

\section{References}

[1] Kirollos, K.S. and Mihaylov, G.M. (2001) Self Appearing Warning Sign Device and Method of Manufacture. USP 6284198 B1.

[2] Feng, L., Musto, C.J., Kemling, J.W., Lim, S.H., Zhong, W. and Suslick, K.S. (2010) Colorimetric Sensor Array for Determination and Identification of Toxic Industrial Chemicals. Anal. Chem, 82, 9433-9440. http://dx.doi.org/10.1021/ac1020886

[3] https://en.wikipedia.org/wiki/

[4] Guin, P.S., Das, S. and Mandal, P.C. (2011) Electrochemical Reduction of Quinones in Different Media: A Review. Inter. J Electrochem., 2011, Article ID: 816202.

[5] Var der Zee, F.P., Bouwman, R.H.M., Strik, D.P.B.T.B., Lettinga, G. and Field, J.A. (2001) Application of Redox Mediator to Accelerate the Transformation of Reactive Azo Dye in Anaerobic Bioreactor. Biotech. \& Bioengineer, 75, 691-701. http://dx.doi.org/10.1002/bit.10073

[6] Cheng, M., Yang, X., Chen, C., Zhao, J., Zhang, F. and Sun, L. (2013) Dye-Sensitized Solar Cells Based on Hydroquinone/Benzoquinone as Bio-Inspired Redox Couple with Different Counter Electrodes. Phys. Chem. Chem. Phys., 15, 15146-15152. http://dx.doi.org/10.1039/c3cp51980e

[7] CIE, Colorimetry, 3rd Edition, Commission internationale de l’Eclairage, CIE Central Bureau, 2004.

[8] Oses, J., Fabregat-Vazquez, M., Pedroza-Islas, R., Tomas, S.A., Cruz-Orea, A. and Mate, J.I. (2009) Development and Characterization of Composite Edible Films Based on Whey Protein Isolate and Mesquite Gum. Journal of Food Engineering, 92, 56-62. http://dx.doi.org/10.1016/j.jfoodeng.2008.10.029

[9] Mills, A., Lawrie, K., Bardin, J., Apedaile, A., Skinner, G.A. and O’Rourke, C. (2012) An $\mathrm{O}_{2}$ Smart Plastic Film for Packaging. Analyst, 137, 106-112. http://dx.doi.org/10.1039/C1AN15774D 